\title{
Struma Ovarii with Pseudo-Meigs' Syndrome and Raised Cancer Antigen-125 Levels Masquerading as an Ovarian Carcinoma Case report and literature review
}

Surekha Yadav, ${ }^{1}$ Reena Tomar, ${ }^{1}$ Nidhi Verma, ${ }^{1}$ Nita Khurana, ${ }^{1}$ Rewa Triathi ${ }^{2}$

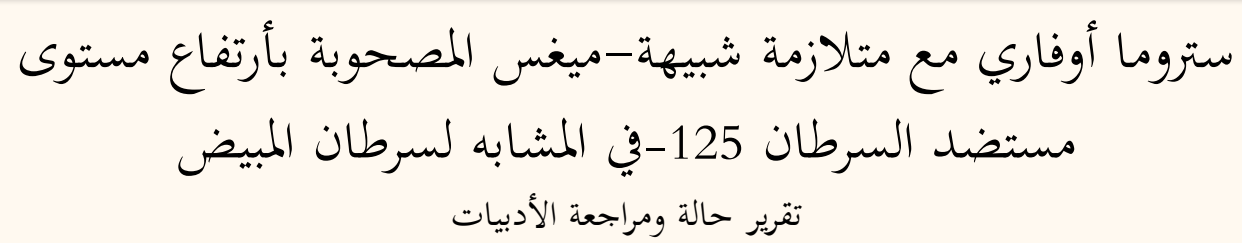

سوريخا يـاداف، رينا تومار، نيدهي فيرما، نيتا خورانا، ريوا تريباثي

ABSTRACT: The monodermal teratoma struma ovarii is a rare ovarian tumour; however, struma ovarii presenting with pseudo-Meigs' syndrome and raised cancer antigen (CA)-125 levels is even rarer. In elderly patients, this presentation can potentially lead to a misdiagnosis of a malignant ovarian carcinoma, resulting in unnecessary extensive surgery. We report a 55-year-old female who presented to the Lok Nayak Jai Prakash Narayan Hospital, New Delhi, India, in 2016 with progressive abdominal discomfort, fatigue and abdominal distention. Clinical and radiological features were indicative of a malignant ovarian tumour and ascites. Serum CA-125 levels were elevated at $258 \mathrm{U} / \mathrm{mL}$. A left-sided salpingo-oophorectomy was performed, after which the serum CA-125 levels normalised. There was no evidence of recurrence at a six-month follow-up. A frozen section procedure confirmed the diagnosis of a struma ovarii. This rare condition should be considered as a differential diagnosis in patients presenting with ovarian masses, ascites and raised CA-125 levels.

Keywords: Ovarian Cancers; Struma Ovarii; Meigs' Syndrome; Carcinoma; Ascites; Frozen Section; Case Report; India.

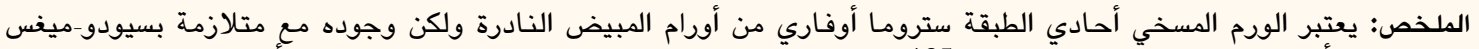

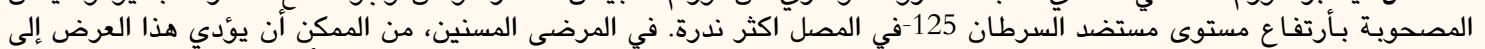

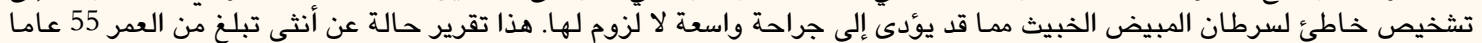

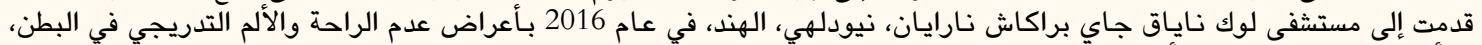

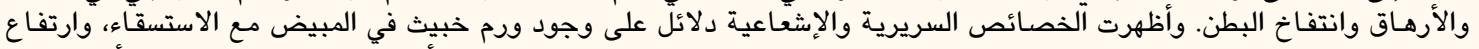

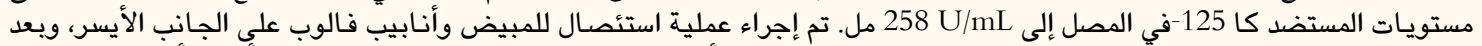

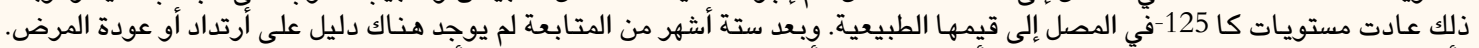

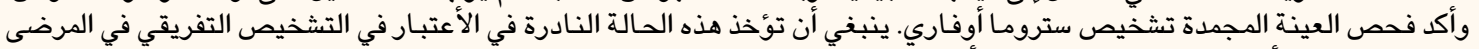

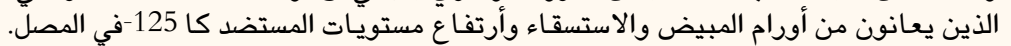

الكلمات المفتاحية؛ سرطان المبيض؛ ستروما أوفاري؛ متلازمة ميغس؛ سرطان؛ استسقاء؛ العينة المجمدة؛ تقريرحالة؛ الهند.

S TRUMA OVARII ARE MATURE OVARIAN TERATOMAS derived from one type of germ cell; these monodermal variants account for $>5 \%$ of mature teratomas and $0.3-1 \%$ of ovarian tumours. ${ }^{1}$ These types of tumours predominantly consist of thyroid tissue ( $>50 \%$ of the overall ovarian mass) and the usual age of presentation is during the fifth and sixth decades of life. ${ }^{1}$ The reported rate of malignant transformation is $5-37 \%$, in which the struma ovarii transforms into a thyroid-type carcinoma. ${ }^{2}$ The usual presentation of struma ovarii is as an abdominopelvic mass, although it may present with hyper- thyroidism in approximately $5 \%$ of cases. $^{3}$ Radiologically, a benign ovarian mass presenting with ascites and raised cancer antigen (CA)-125 levels can be misdiagnosed as a malignant ovarian tumour., ${ }^{2,45}$ In such cases, a correct intraoperative diagnosis can prevent extensive surgery.

\section{Case Report}

A 55-year-old female presented to the Lok Nayak Jai Prakash Narayan Hospital, New Delhi, India, in 2016 with progressively increasing abdominal discomfort, 


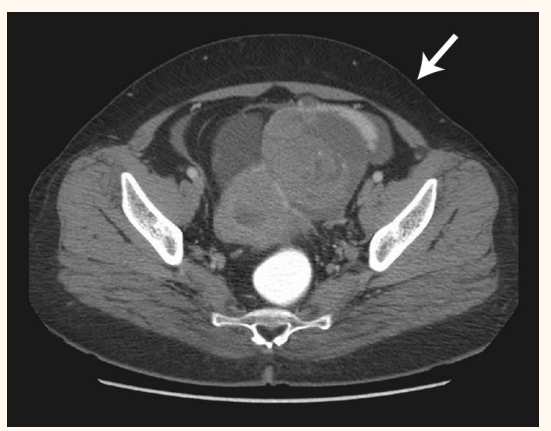

Figure 1: Abdominal computed tomography of a 55-year-old female with progressive abdominal discomfort and abdominal distention showing a left adnexal mass (arrow).

fatigue and abdominal distention for the preceding five months. She had been postmenopausal for the last five years. She had three children, with her last childbirth having taken place 28 years previously. Her medical, surgical and family history was normal. A pelvic examination revealed a left-sided pelvic mass of $6 \times 5 \times 5 \mathrm{~cm}$ in which the uterus moved with the mass. Her CA-125 level was $258 \mathrm{U} / \mathrm{mL}$ (normal value: $<35 \mathrm{U} / \mathrm{mL}$ ). All haematological investigation results were within normal range. A chest X-ray was unremarkable, with no indications of pleural effusion.

Ultrasonography revealed a left-sided solidcystic adnexal mass measuring $6 \times 5 \times 3.5 \mathrm{~cm}$. The right-sided adnexa, uterus and cervix appeared normal. There was $680 \mathrm{~mL}$ of free fluid in the recto-uterine pouch. Computed tomography of the pelvis revealed a left-sided heterogeneously enhancing solid-cystic pelvic mass measuring $6.2 \times 5 \times 4 \mathrm{~cm}$ [Figure 1]. The left ovary was not visualised separately. There was no evidence of organomegaly or lymphadenopathy. Overall, the radiological findings were suggestive of a malignant mass. A total of $500 \mathrm{~mL}$ of peritoneal serous fluid was removed via abdominal paracentesis. Cytological examination of this fluid indicated only reactive mesothelial cells with a few leukocytes, with no malignant cells identified.

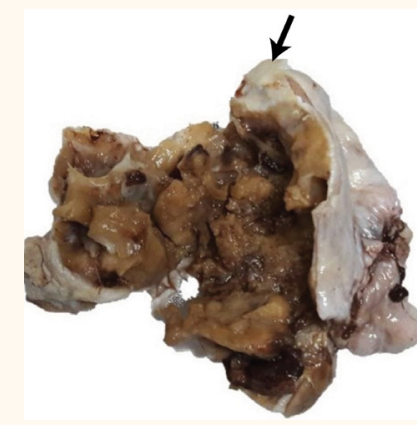

Figure 2: Photograph showing an encapsulated left ovarian solid-cystic mass (arrow), which had replaced the entire normal ovarian parenchyma.

An exploratory laparotomy was performed. The left-sided adnexal mass measured $6 \times 5 \times 4.5 \mathrm{~cm}$ and was solid-cystic, with a smooth external surface. The uterus and cervix were normal and there was no evidence of intraperitoneal spread to the omentum, liver or appendix. The patient subsequently underwent a left-sided salpingo-oophorectomy and the excised specimen was sent for frozen analysis to rule out malignancy. During the postoperative period, the results of a thyroid function test were normal. The patient recovered well after surgery and there was no evidence of any re-accumulation of ascitic fluid. By the eighth postoperative day, her postoperative CA-125 levels had normalised. At a six-month follow-up, there were no signs of recurrence of the ovarian mass.

On gross examination, the excised ovarian mass measured $6 \times 5 \times 4 \mathrm{~cm}$ and there was no evidence of haemorrhage, bone, cartilage or hair. The external surface was smooth and glistening white. The cut surface revealed a solid-cystic mass which had replaced the entire ovarian parenchyma [Figure 2]. An omental biopsy and peritoneal washing was performed on the excised specimen, with benign results. The scrape smears showed cuboidal cells forming thyroid follicles and monolayered sheets in a thin colloid background [Figure 3A]. The frozen section revealed that the specimen was composed
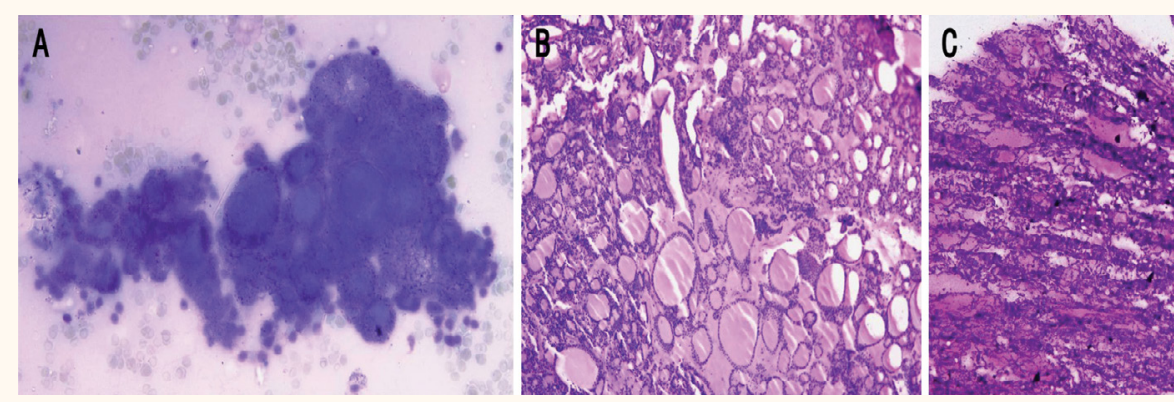

Figure 3: A: Toluidine blue scrape smear at x20 magnification showing thyroid follicles with colloid in the background. B: Haematoxylin and eosin (H\&E) stained frozen section at x40 magnification showing variable-sized colloid-filled thyroid follicles. C: H\&E stained frozen section at x20 magnification showing various thyroid follicles. 

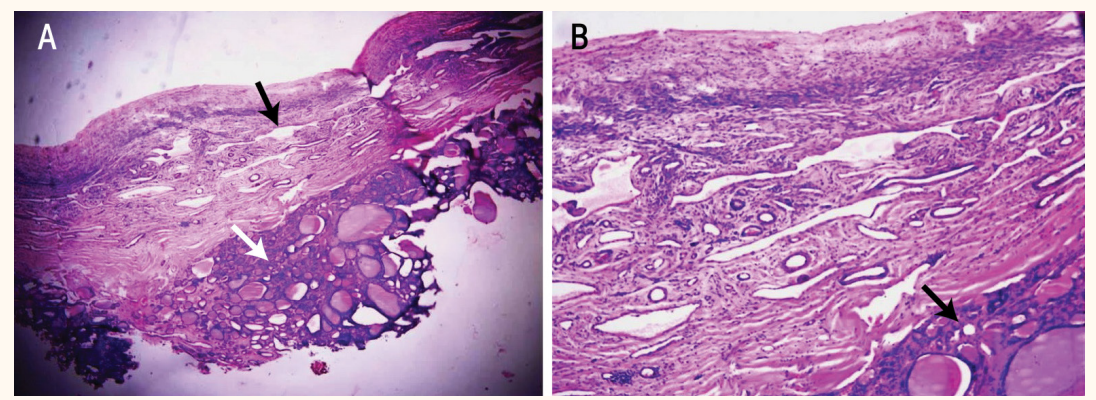

Figure 4: A: Haematoxylin and eosin (H\&E) stained paraffin section at x10 magnification showing colloid-filled thyroid follicles (white arrow) and compressed normal thyroid parenchyma at the periphery (black arrow). B: H\&E stained paraffin section at $\times 40$ magnification showing normal ovarian parenchyma at the periphery (arrow) with central thyroid parenchyma.

of colloid-filled follicles of various sizes, resembling thyroid follicles [Figures 3B and C]. Based on analysis of the scrape smears and frozen section, a provisional diagnosis of struma ovarii was made. The remaining specimen underwent routine histopathological examination. Microscopically, the tumour was lobular and composed of central normal thyroid parenchymal tissue with peripherally compressed normal ovarian tissue [Figure 4]. The tumour cells were cuboidal to the low columnar cells with eosinophilic cytoplasm and minimal cytological atypia. The intervening stroma was oedematous. There was no evidence of papillary carcinoma or mitotic figures. These histological features confirmed the diagnosis of a struma ovarii.

\section{Discussion}

Meigs' syndrome is a rare disorder involving the co-occurrence of a fibroma or fibroma-like tumour with ascites and hydrothorax, in which the ascites and hydrothorax resolve following removal of the tumour; in contrast, pseudo-Meigs' syndrome consists of ascites, pleural effusion with serous or serosanguinous fluid and tumours other than fibromas. ${ }^{6,7}$ In their report of a case of pseudo-Meigs' syndrome due to a uterine leiomyoma, Amant et al. suggested various mechanisms which might cause ascites in such cases, including lymphatic obstruction by the tumour, irritation of the peritoneum by the tumour, the release of toxins and inflammatory products, hypoalbuminemia and decreased venous and lymphatic drainage. ${ }^{7}$ In addition, the use of a dye test was advocated to determine the exact cause of pleural effusion. In their case, Amant et al. noted that the pleural effusion originated from the mechanical transfer of ascitic fluid through a diaphragmatic opening. ${ }^{7}$ However, the aetiology of ascites and pleural effusion in patients with struma ovarii is still unclear.

Although it is usually a serum tumour marker of great diagnostic importance, CA-125 has poor specificity in the diagnosis of epithelial ovarian cancers since it is also raised in other malignancies, a few benign conditions and certain physiological states. ${ }^{8}$ The mechanism behind raised CA-125 levels in cases of Meigs' and pseudo-Meigs' syndromes is still not understood, although Mui et al. have postulated that it is the result of free fluid irritation leading to inflammation of the pleural and peritoneal surfaces. ${ }^{9}$ In the current case, features of a complex solid-cystic pelvic mass with ascites and raised serum CA-125 levels in a middle-aged woman were initially suggestive of a pelvic malignancy. However, the CA-125 levels normalised on the eighth postoperative day without any adjuvant therapy. Postoperatively, a thyroid hormone profile was also normal. Unfortunately, a preoperative thyroid hormone profile was not performed as the patient was asymptomatic and a struma ovarii was not considered during the differential diagnosis.

In an extensive search of the literature, Obeidat et al. presented 26 struma ovarii cases associated with ascites and raised CA-125 levels. ${ }^{10}$ All of these patients were initially thought to have malignant tumours; in addition, in all cases, the ascites disappeared completely and CA-125 levels returned to normal after the removal of the tumour. Most of the diagnosed patients were in their fifth decade or older, with the exception of one patient who was 31 years old. ${ }^{11}$ The tumour sizes ranged between $4-23 \mathrm{~cm}$ in the greatest dimension, with an average size of $12 \mathrm{~cm} .{ }^{10}$ In all cases, the volume of ascitic fluid was over $1 \mathrm{~L}$, except for five cases.,12-15 The most common presenting symptom was abdominal distension. ${ }^{2-4,9,10,12,13,15-22}$ Pleural effusion was noted in 15 cases. ${ }^{10}$ In one case, the struma ovarii was an incidental finding. ${ }^{14}$ No relationship was reported between pleural effusion and the volume of ascites. ${ }^{10}$ The mean follow-up period was approximately 8 months, ranging from 1-36 months. ${ }^{4,5,9-11,15,17,18,20,22-25}$ Most cases were treated via total abdominal hysterectomy and bilateral 
salpingo-oophorectomy. ${ }^{2-5,9,11,12,15,17-22,24,25}$ Only three patients underwent conservative surgery. ${ }^{13,14,23}$ In the present case, the patient underwent conservative surgery in the form of a salpingo-oophorectomy, as there was no evidence of malignancy according to the frozen section analysis. All other organs were healthy-looking with no adhesions or evidence of organomegaly or lymphadenopathy.

Scrape smears and frozen sections are of great importance in accurately diagnosing ovarian neoplasms and planning surgical management. According to various studies, the accuracy of an intraoperative frozen section varies from $80 \%$ to $>90 \% .{ }^{26}$ A scrape smear of a struma ovarii shows benign follicular epithelial cells forming follicles of various sizes and a monolayered sheet in a colloidfilled background. ${ }^{27}$ A frozen section also shows the classical pattern of variable-sized follicles filled with colloid. Malignant transformation in struma ovarii usually results in a thyroid-type carcinoma (i.e. a papillary and follicular carcinoma), which is ruled out via histological examination. ${ }^{15}$ The criteria for malignancy in struma ovarii are the same as those of a thyroid carcinoma. ${ }^{27}$ Nuclear features such as nuclear grooves are more clearly visible on scrape smears and their absence rules out a papillary carcinoma. In addition, follicular carcinomas have capsular breaches and vascular invasion. ${ }^{27}$

\section{Conclusion}

Intraoperative frozen section and scrape cytology analyses are of critical importance in cases of ovarian masses wherein the clinical, biochemical and radiological features indicate a malignant aetiology. In the present case, a correct diagnosis due to an intraoperative frozen section analysis prevented radical surgery in a patient with struma ovarii, pseudoMeigs' syndrome and raised CA-125 levels. This rare presentation of a struma ovarii should therefore be considered during the differential diagnosis of a patient with a suspected ovarian carcinoma.

\section{References}

1. Md Nor NB, Kusumoto T, Inoue S, Nakamura K, Seki N, Hongo A, et al. Three cases of struma ovarii underwent laparoscopic surgery with definite preoperative diagnosis. Acta Med Okayama 2013; 67:191-5.

2. Loizzi V, Cappuccini F, Berman ML. An unusual presentation of struma ovarii mimicking a malignant process. Obstet Gynecol 2002; 100:1111-12 doi: 10.1097/00006250-200211001-00022.
3. Guida M, Mandato VD, Di Spiezio Sardo A, Di Carlo C, Giordano E, Nappi C. Coexistence of Graves' disease and benign struma ovarii in a patient with marked ascites and elevated CA-125 levels. J Endocrinol Invest 2005; 28:827-30. doi: 10.1007/BF03347575.

4. Rim SY, Kim SM, Choi HS. Struma ovarii showing clinical characteristics of ovarian malignancy. Int J Gynecol Cancer 2005; 15:1156-9. doi: 10.1111/j.1525-1438.2005.00328.x.

5. Leung YC, Hammond IG. Limitations of CA125 in the preoperative evaluation of a pelvic mass: Struma ovarii and ascites. Aust N Z J Obstet Gynaecol 1993; 33:216-17. doi: 10.1111/j.1479-828X.1993.tb02400.x.

6. Macciò A, Madeddu C, Kotsonis P, Pietrangeli M, Paoletti AM. Large twisted ovarian fibroma associated with Meigs' syndrome, abdominal pain and severe anemia treated by laparoscopic surgery. BMC Surg 2014; 14:38. doi: 10.1186/1471-2482-14-38.

7. Amant F, Gabriel C, Timmerman D and Vergote I: PseudoMeigs' syndrome caused by a hydropic degenerating uterine leiomyoma with elevated CA 125. Gynecol Oncol 2001; 83:153-7. doi: 10.1006/gyno.2001.6251.

8. Jacobs I, Bast RC Jr. The CA 125 tumour-associated antigen: A review of the literature. Hum Reprod 1989; 4:1-12. doi: 10.1093/oxfordjournals.humrep.a136832.

9. Mui MP, Tam KF, Tam FK, Ngan HY. Coexistence of struma ovarii with marked ascites and elevated CA-125 levels: Case report and literature review. Arch Gynecol Obstet 2009; 279:753-7. doi: 10.1007/s00404-008-0794-1.

10. Obeidat R, Perren TJ, Saidi SA. Struma ovarii associated with pseudo-Meigs' syndrome and elevated serum CA 125: A case report and literature review. Gynecol Obstet 2012; 2:129. doi: 10.4172/2161-0932.1000129.

11. Huh JJ, Montz FJ, Bristow RE. Struma ovarii associated with pseudo-Meigs' syndrome and elevated serum CA 125. Gynecol Oncol 2002; 86:231-4. doi: 10.1006/gyno.2002.6741.

12. Bokhari A, Rosenfeld GS, Cracchiolo B, Heller DS. Cystic struma ovarii presenting with ascites and an elevated CA-125 level: A case report. J Reprod Med 2003; 48:52-6.

13. Hurlow RA, Greening WP, Krantz E. Ascites and hydrothorax in association with struma ovarii. Br J Surg 1976; 63:110-12. doi: 10.1002/bjs.1800630205.

14. Mancuso A, Triolo O, Leonardi I, De Vivo A. Struma ovarii: A rare benign pathology which may erroneously suggest malignancy. Acta Obstet Gynecol Scand 2001; 80:1075-6. doi: 10.1034/j.1600-0412.2001.801121.x

15. Rana V, Srinivas V, Bandyopadhyay S, Ghosh SK, Singh Y. Bilateral benign non functional struma ovarii with pseudoMeigs' syndrome. Indian J Pathol Microbiol 2009; 52:94-6. doi: 10.4103/0377-4929.44978.

16. Lenehan PM, Colgan T, Vernon CP. Struma ovarii presenting with ascites: A difficult diagnostic problem. Eur J Gynaecol Oncol 1985; 6:89-91.

17. Amr SS, Hassan AA. Struma ovarii with pseudo-Meigs' syndrome: Report of a case and review of the literature. Eur J Obstet Gynecol Reprod Biol 1994; 55:205-8. doi: 10.1016/00282243(94)90039-6.

18. Bethune M, Quinn M, Rome R. Struma ovarii presenting as acute pseudo-Meigs syndrome with an elevated CA 125 level. Aust N Z J Obstet Gynaecol 1996; 36:372-3. doi: 10.1111/j.1479828X.1996.tb02734.x

19. Jotkowitz MW, Gee DC. Unique case of massive ascites, extreme elevation of serum CA 125 tumour marker. Aust N Z J Obstet Gynaecol 1993; 33:453-4. doi: 10.1111/j.1479828X.1993.tb02139.x. 
20. Long CY, Chen YH, Chen SC, Lee JN, Su JH, Hsu SC. PseudoMeigs syndrome and elevated levels of tumor markers associated with benign ovarian tumors: Two case reports. Kaohsiung J Med Sci 2001; 17:582-5.

21. Mantouvalos C, Metallinos C, Gouskos A. Struma ovarii with Meigs' syndrome. Aust N Z J Obstet Gynaecol 1982; 22:101-2. doi: 10.1111/j.1479-828X.1982.tb01414.x.

22. Jiang W, Lu X, Zhu ZL, Liu XS, Xu CJ. Struma ovarii associated with pseudo-Meigs' syndrome and elevated serum CA 125: A case report and review of the literature. J Ovarian Res 2010; 3:18. doi: 10.1186/1757-2215-3-18.

23. Loizzi V, Cormio G, Resta L, Fattizzi N, Vicino M, Selvaggi L. Pseudo-Meigs syndrome and elevated CA125 associated with struma ovarii. Gynecol Oncol 2005; 97:282-4. doi: 10.1016/j. ygyno.2004.12.040
24. Mitrou S, Manek S, Kehoe S. Cystic struma ovarii presenting as pseudo-Meigs' syndrome with elevated CA125 levels: A case report and review of the literature. Int J Gynecol Cancer 2008; 18:372-5. doi: 10.1111/j.1525-1438.2007.00998.x.

25. Obeidat BR, Amarin ZO. Struma ovarii with pseudo-Meigs syndrome and elevated CA125 levels. J Obstet Gynaecol 2007; 27:97-8. doi: 10.1080/01443610601076267.

26. Geomini P, Bremer G, Kruitwagen R, Mol BW. Diagnostic accuracy of frozen section diagnosis of the adnexal mass: A metaanalysis. Gynecol Oncol 2005; 96:1-9. doi: 10.1016/j. ygyno.2004.09.042

27. Nogales F, Talerman A, Kubik-Huch RA, Tavassoli FA, Devouassoux-Shisheboran M. Germ cell tumours. In: Tavassoli FA, Devilee P, Eds. Pathology and Genetics: Tumours of the breast and female genital organs. Lyon, France: International Agency for Research on Cancer Press, 2003. Pp. 163-75. 